\title{
HEALTH FAIR: COMMUNITY INVOLVEMENT AND OWNERSHIP IN EVENT PLANNING
}

\author{
ABU HASIB MOSTAFA JAMAL, ZEENAT SULTANA \& A. K. SHAFIQUR RAHMAN \\ Department of Public Health, Bangladesh Center for Communication Programs (BCCP), Bangladesh
}

\begin{abstract}
Over the years, Bangladesh Center for Communication Programs (BCCP) has been working on Behaviour Change Communication (BCC) and Community Mobilization for Bangladesh communities; BCCP is partnering with NGO Health Service Delivery Project (NHSDP), that delivers essential healthcare services across the country through a network of 25 NGOs covering $15 \%$ of the total population through Surjer Hashi (SH) clinics. BCCP is working with NHSDP on community mobilization for reaching out to different stakeholders, creating partnerships in order to identity community resources, health needs and promoting health seeking behaviour at household level. To accelerate community ownership and demonstrate role of the stakeholders in mobilizing resources for promoting model community action - a series of activities had been carried out under a community congregation named "Health Fair"; which was planned, organized and facilitated by community groups. This was an interactive event showcasing health messages and listening to community voices. A total of 25 Health Fairs had been held. With community involvement, the NGOs leveraged social capital, volunteerism, government ownership and private stakeholders' involvement. The perception analysis of attending audiences showed this as a highly successful event where $79.5 \%$ respondents commented this as useful for them, $95.7 \%$ were willing to share information with others and $99 \%$ thought that this kind of fair should be arranged in future. The participation of the communities is key to the success. Creating community ownership can work for discovering and unfolding of the community resources for the sustainability of health promotion.

Keywords: community, stakeholders, mobilization, action, resource, ownership, sustainability, health, involvement, promotion.
\end{abstract}

\section{INTRODUCTION}

Bangladesh has made significant strides in the health sector, and is on track to reach Millennium Development Goals 1, 4 and 5, including a steady rise in life expectancy at birth. Attention is now turning to the Sustainable Development Goals, particularly Goal \# 3 which aims at ensuring healthy lives and promoting well-being for all at all ages [1]. The Alma Ata Declaration in 1978 framed community involvement as central to primary healthcare [2]. It has also been enshrined as an important standard within rights based approaches to health that has a basic value in and of itself [3]. Since these landmark agreements reinforce community involvement, considerable experience has been built regarding it, with plenty of argue and reflection about its definition, rationale and outcomes [4]-[12]. Community involvement can be instrumental as working with communities can help make interventions more relevant to local needs, informed by local knowledge and priorities, and therefore more effective. More necessarily, depending on the social processes involved, it can also be transformative, helping to empower and emancipate marginalized communities. At the same time, community involvement without attention to power relations can distort participation from its developmental aims, exacerbate existing patterns of exclusion and further entrench inequities. While there is growing consensus on the value of community involvement in health systems, there is variation in how communities are defined and understood. While communities are often defined as being geographic, such as in villages or neighbourhoods, they are not necessarily territorial, as they can also include social groups united by activities 
or interests, and in a range of spaces. The Latin word 'communitas' combines the terms 'with/together' with 'gift', as a broad term for fellowship or organized society. In this sense, Campbell and Jovchelovitch defined as communities are constituted by those with a shared social identity; that is of members with the same set of social representations, which are the meanings, symbols and aspirations through which people make sense of their world [13]. These are not purely markers of affinity, but also governed by power relations (Navarro [14]). In this sense, communities are also heterogeneous and constitute sites of social exclusion [15], [16]. These social conditions are not permanent. Communities are also sites of empowerment, where unequal relations can be challenged [17], [18]. Though a defining element in assessing community involvement is the level of control or power that communities command in an initiative (Joffe [18]), the terminology that categorizes the processes and conditions by which communities are involved also at times blurred, ranging from mobilization to empowerment. Some view community mobilization as mainly externally driven (Rifkin [20]), while others define it as how communities plan, carry out, and evaluate activities on a participatory and sustained basis to improve their health and other needs, either on their own initiative or stimulated by others (O'Rourke et al. [21]). Beyond community mobilization lies community empowerment, the expansion of capability to participate in; negotiate with; influence, control, and hold accountable institutions that affect the wellbeing of the community. It is through empowerment that communities gain mastery over their lives and change their social and political environment to improve their health and quality of life (Wallerstein [22]). Since multiple reviews have argued the value of community participation [4]-[12], evaluations have largely focused on health outcomes. None assess the extent to which community participation figures in research on health systems interventions. It is not the intention of the review to provide a comprehensive catalogue of the literature on community participation, as this has already been done by others [4], [5], [10], [20], [23], [24]. Hence, the purpose of this research is to experience how people's congregation accelerates community ownership and demonstrates role of the stakeholders in mobilizing resources for promoting model community health practice through Health Fairs, also to see the level and scope of community involvement in event planning for health awareness intervention.

Over the years Bangladesh Center for Communication Programs (BCCP) has been working on Behaviour Change Communication (BCC) and Community Mobilization (CM) for Bangladesh communities in continuation of which they are partnering with NGO Health Service Delivery Project (NHSDP), that delivers essential healthcare services across the country through 399 static and 10186 satellite Surjer Hashi (SH) clinics through a network of 25 NGOs covering 15\% [25], of the total population in Bangladesh. The project is funded by USAID and DFID. Around 5000 NGO staff and 7350 community volunteers are engaged in delivering these services, creating awareness ensuring high quality and a strong commitment to contribute in improvement of health and population sector. BCCP is working with NHSDP on BCC and CM to design for reaching out to different stakeholders and creating partnerships in order to identity their community resources, health needs, promoting health seeking behaviour at household level and capacity building of NGOs on BCC and CM.

\subsection{Purpose}

The purpose of this research is to experience how people's congregation accelerates community ownership and demonstrates role of stakeholders in mobilizing resources for promoting model community health practice through Health Fairs, also to see the level and scope of community involvement in event planning for health awareness intervention. 


\section{METHOD}

A series of activities were carried out under a community congregation named "Health Fair" which were planned, organized and facilitated with active involvement of the community leaders, social elites, community groups, and local government officials. These were educational and interactive event that showcased different health messages and encouraged listening to community voice. The Health Fair has two parts; the first part with formal inauguration while the second part has daylong enter-educative event. The daylong event included health dialogues, storytelling by the champions, traditional cultural shows, drama shows, quiz competition, outdoor games for children, demonstrating benefit of positive health behaviour, and displaying stalls of health services offered by SH clinics. However, in some clinics continued the fair for two to three days. Each Health Fair was participated by around 3500 number of community people. Out of these, 680 Health Fair attendees were interviewed from 25 health fairs and they were selected on random basis.

\subsection{Key approaches of Health Fair}

The Health Fairs were held in a festive mood engaging the communities in each of the clinic catchment population. The following were the main key approached/features:

a) Forming Health Fair organizing committee

b) Massive promotions on Health Fair event

c) Involve local educational institutions

d) Maintain collaboration and coordination with GoB, Local Government and NGOs

e) Mobilize sponsorship/CSR

f) Recognition of satellite clinics space donors, Community Service Providers (CSP), Surjer Hashi Community Support Groups (SHCSG) and newly married couples

g) Active engagement of community volunteers as a vehicle to generate demand for health services

\subsection{Steps of Health Fair}

As mentioned, there were 25 Health Fairs held in 25 SH clinics' locations of 23 partner NGOs for SH network across the country. The $25 \mathrm{SH}$ clinics' locations were selected from $388 \mathrm{SH}$ clinics based on certain criteria as follows, which located throughout the country:

- Clinics where performance of certain key service indicators were low despite the density of catchment population were significant in numbers

- Clinics located in a strategic location where a nearby open field was available for the fair to accommodate $1000-2000$ audience at a time

- Availability of other health project(s) implementing in the same or adjacent areas with scope to mobilize their participation in the fair

- Scope to mobilize the GOB counterparts to support inorganizing the fair

Preference was given to those clinics where community support group for SH clinics (SHCSG) were active and clinic staff received BCC and CM training.

The SH clinic ensured active involvement of community stakeholders, team leaders and active members of SHCSG, local cultural groups in planning and organizing the Health Fair, managing resources and sharing their voices and experiences. A Health Fair committee was formed for each event comprised of that locality as members from community stakeholders, local elected leaders, government officers, students and local level cultural personnel. 


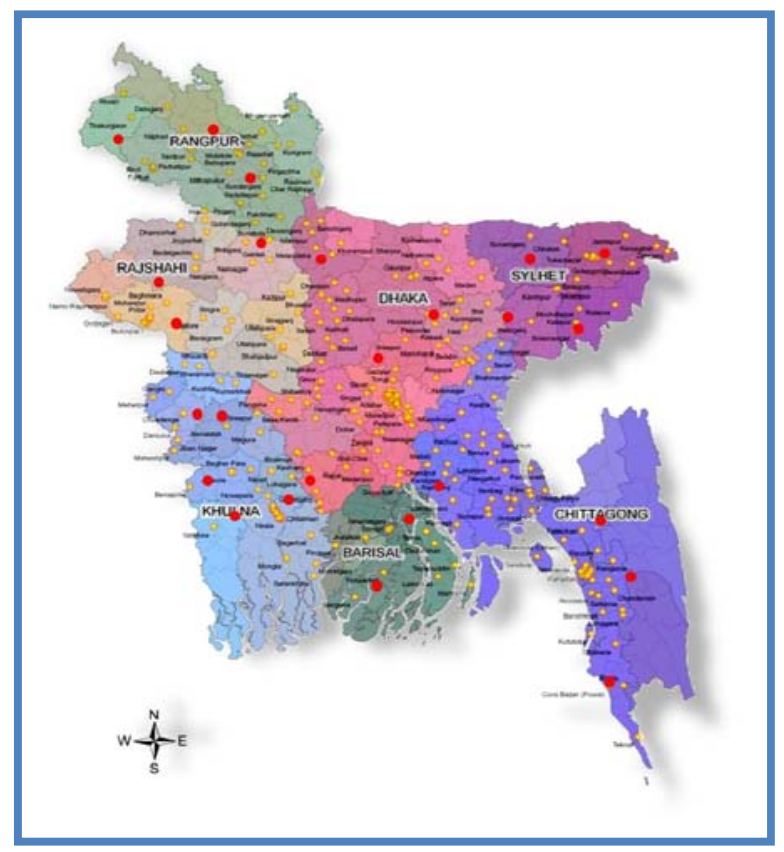

Figure 1: Red dots are locations of Health Fairs.

The Fair also involved other NGOs who were working on health, nutrition and family planning for displaying their services. The organizing committee also formed volunteer groups with school and college students, and scouts who worked as guide for the visitors, maintained the discipline within fair, and were engaged to promote health messages. To attract more visitors, selection of venue for the Health Fair was important. The Health Fair was held in an open place such as playground or any open field near to a busy crossroads, which was easy to access and close to densely populated neighbourhood so that a good number of nearby residents could visit the fair and take the services. The fairs also managed space to accommodate the stalls and venues were community sponsored. The committee listed down and invited all relevant key stakeholders from community, government, NGOs, local media (print and electronic) and community support groups members of SH clinics for their presence and endorsement in promoting community health practice.

These fairs were decorated with banner, festoon and colourful cut-outs to make the event attractive and bring a festive mode. Enter-educative audio-visual shows on health awareness were displayed; BCC materials and service charge discount forms were distributed creating a buzz in this event. The respective SH clinic and organizing committee took special initiatives to mobilize local resource and manage sponsorship that contributed in managing the fair. Sponsorship were made in many forms: providing free venue, awarding the champion, paying the cultural team; giving prize to the quiz contest winners; providing free transportation; arranging games, providing logistics to decorate the venue, providing refreshment for the volunteers etc. Promotional activities for the Health Fair were usually initiated 2-3 days before the actual event through mike announcements, distributing leaflets, house to house visits and during outreach activities of the clinics. The invitation was done mostly by the members of the organizing committee and the SH clinic staffs. 


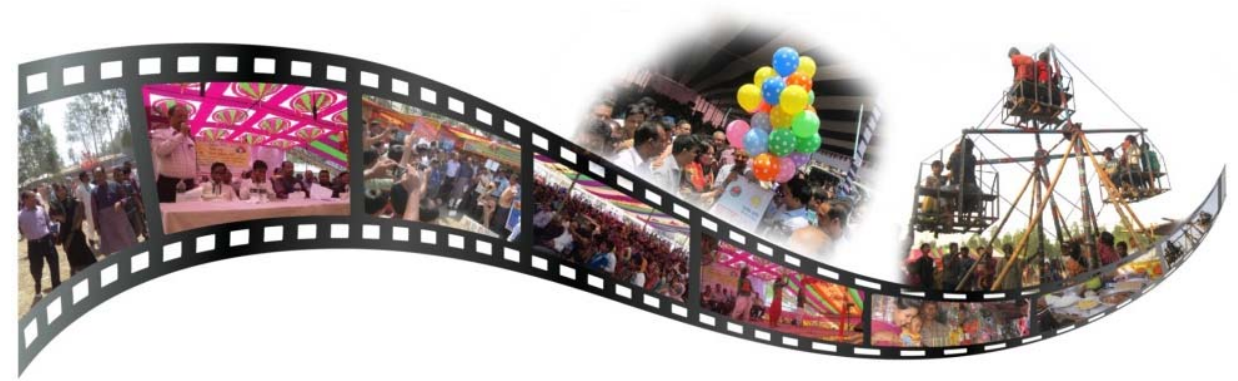

Figure 2: Some momentum of festive mood in the Health Fair.

The Health Fair committee commonly invited the government officials like Deputy Commissioner, Civil Surgeon, Deputy Director Family Planning, Police Commissioners etc, peoples' representatives like Member of Parliament, City Mayor, Upazila Chairman and the local elites to inaugurate the fair. Their participation in the fair was critically valued by the local people. In the Health Fair SH clinics and other NGOs used to offer essential health care services at a discount price for those who visited the fair. In the fair there was provision for quiz competitions on health information and awarding the winners. This has attracted more visitors to the fair and in turn provided them opportunity to expose with health messages. During the fair health related street drama and cultural shows were performed which helped to attract more people to visit the Health Fair. The drama was performed by the local cultural team and clinic staff. The committee members were involved in selecting local talents to perform in the shows. The health messages delivered through this event were tailored into local language to make them more lively and familiar for the audience. There were story telling sessions where the satisfied clients of SH clinics, best performing community health volunteers, proactive SHCSG leaders were invited to narrate their stories to the audience as a "success stories".

Clinic arranged Audio-Visual (AV) van show with the support of department of Mass Communication, Ministry of Information. They displayed promotional videos of SH services through AV Van at the distant community that has drawn attention of huge number of people to visit the Health Fair. In some locations, the local cable TV network gave scroll message with the news of Health Fair and also showed videos on the SH services in a discount price that promoted the Health Fair greatly. Each of the fairs was supervised by the organizing committee; besides the BCC experts of NHSDP also provided technical support and monitored these events using a standard checklist. The SH clinics documented the process of Health Fairs with lessons learned in a standard format. They also documented what strategy they applied to involve the community stakeholders; how they mobilized resources and what were their recommendations. Besides they also conducted exit-interview with randomly selected audiences of the Health Fair with a standard set of questions to assess the successes and document the lessons learned from these fairs.

\section{RESULTS}

A total of 25 Health Fairs were held at different SH clinic locations across the country. The Health Fair event revealed that NGOs can really leverage social capital and community volunteerism, government sponsorship and ownership and private stakeholders' involvement 
in public health programs. They can work for discovering and unfolding of the resources that exists in the community throughout SH network in 399 locations of Bangladesh.

It is evident that the key stakeholders of the community were involved actively in organizing the Health Fair. The fair committee played significant role in planning and organizing the event. They also positively influenced participation of high level government officials as well as public representatives that resonated their ownership of the program. It is visible that considerable community resources could be mobilized for organizing BCC interventions for community health awareness. It was documented that the community sponsored venue, volunteer services, free promotion, cultural talents and awards; all of which added considerable value to the program. It is envisioned that the people are now become more empowered with the health information they receive from various events of Health Fair. Many clinics reported that the number of customers have increased after the Health Fair. The fair also opened a window of opportunity to have CSR from local organizations. In a nutshell Health Fair reflected a sense of 'ownership' among the local stakeholders.

\subsection{Response of attending audience and on-spot feedback}

Each Health Fair was successfully organized by the Surjer Hashi NGOs in their clinics across the country. These one-day, and in some cases multi-day events that attracted thousands of people along with GOB and other stakeholders and gained widespread media attention. In each Health Fair the average attendance was 600 as discussant while thousands of visitors gathered in the events. The events were strongly represented by Members of Parliament, City Corporation and Municipal Mayors, Upazilla and UP Chairmen, school and college students and a variety of community people. District and divisional level GOB officials from health, family planning and administration were also active supporters and participants. These Health Fairs were held in an open field with festive mode close to respective SH clinics.

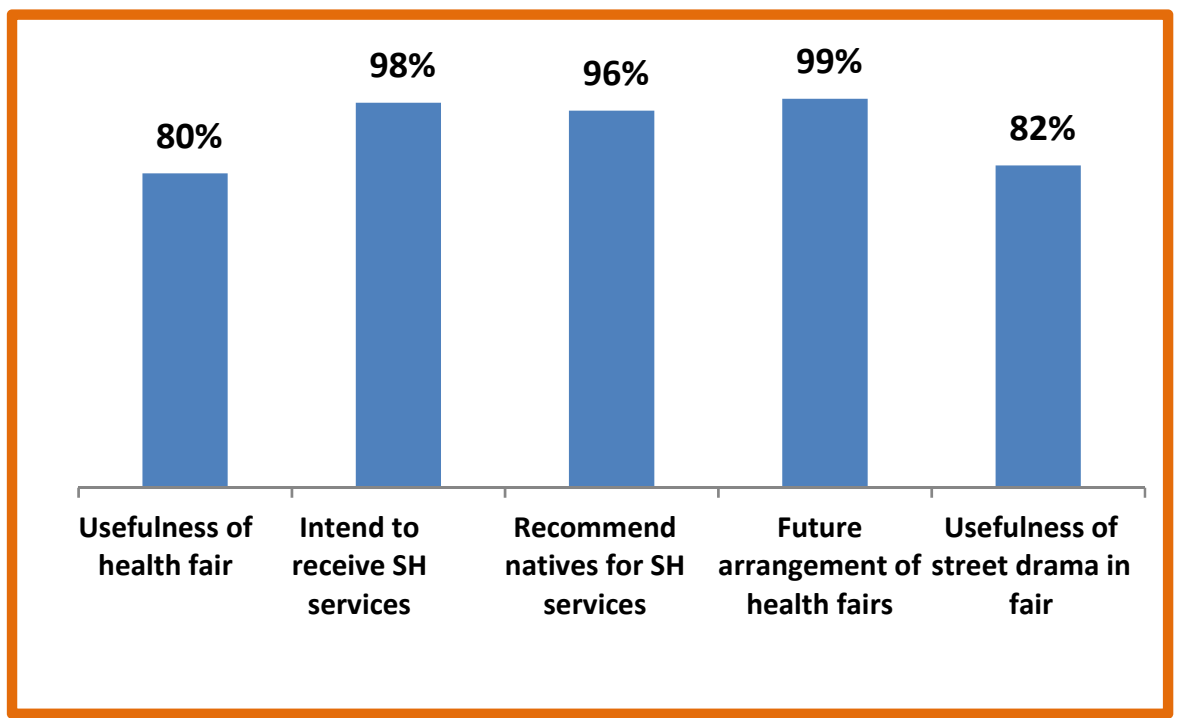

Figure 3: Response of attending audience. 
At the end of each Health Fair a quick people attendance survey took place among 680 attendees using a tool on their observations, feelings and usefulness of the event. The graph shows a very positive feedback on the Health Fair attendees who are keen to advocate for Surjer Hashi clinics and eager to receive health services from the network. Among 680 respondents, 98\% intends to receive services from SH clinic; $96 \%$ people said that they will refer their relatives to receive services from SH clinic. The survey also revealed that street drama is the most effective mode of communication (82\%) to disseminate health messages. NHSDP has provided technical support in organizing different events and ensuring participation of different stakeholders, so that, the clinics would be able to generate support for better health services.

\section{DISCUSSION}

The participation of the communities is key to success of the program. Creating community ownership can work for discovering and unfolding of the resources that exist in the community for the sustainability of Social and Behaviour Change Communication (SBCC) activities. This Health Fair event is a unique example for mobilizing resource mobilization by involving the community which results in the participation of different types of community stakeholders, getting Health Fair venue free of cost, getting several local level sponsorship, voluntarism of local folk and drama team for dissemination of health messages through their performance which was disseminated by local cable TV network free of cost etc. All these activities required advance planning with multidimensional activities in a good team sprit with full commitment and dedication. By nature, Bengali literature and cultural activities are very reach and people are keen to engage in a simple and with open mind to relax and enjoy them. All these Health Fairs capitalise these resources and able to make huge buzz to make significant contribution in delivering health services to people who mostly deserve this at their doorsteps.

\section{CONCLUSION}

Health Fair has never been implemented before at the Surjer Hashi network in Bangladesh. However, the experience of NHSDP, suggests that Health Fairs can successfully contribute to improve autonomy, accountability, focus, and engagement, thus contributing to improve NGO performance. Performance improvement is a complex endeavour that requires motivations of individuals, groups, and organizations, as well as changing the behaviour of individuals, groups, and organizations. Because of this complexity, NHSDP recognizes first, that Health Fair may drive change, but are not directly or solely responsible for this change. Second, to understand how and why change occurs, implementers must apply flexible learning approaches that allow them to learn about and respond to drivers of performance and behaviour change in real-time. This event made the local community confident and capacitated on sustainable development community planning, resource mobilization and participating in practicing and influencing others for model health behaviour. With this tremendous success, all the 25 NGOs planned to conduct around 65 similar Health Fair events in the next year across the country to improve the quality of lives of mass people.

\section{REFERENCES}

[1] Ministry of Health and Family Welfare, Bangladesh, Comprehensive Social and Behaviour Change Communication Strategy, page \# 05, publication year 2016.

[2] World Health Organization, editor Declaration of Alma-Ata. International Conference on Primary Health Care; 1978; Alma Ata: World Health Organization. 
[3] United Nations Committee on Economic Social and Cultural Rights. General Comment No. 14: The Right to the Highest Attainable Standard of Health (Art. 12 of the Covenant) 2000 [08 Jul 2014]. Available from: http://www.refworld.org/docid/ 4538838d0.html.

[4] Rifkin, S.B., Examining the links between community participation and health outcomes: a review of the literature. Health policy and planning. 29, PP 98-106, 2014. doi:10.1093/heapol/czu076 PMID:25274645.

[5] Rosato, M., Laverack, G., Grabman, L.H., Tripathy, P., Nair, N., Mwansambo, C. et al., Community participation: lessons for maternal, newborn, and child health. Lancet, 372(9642), 962-71, 2008. doi: 10.1016/S0140-6736(08)61406-3 PMID: 18790319.

[6] Marston, C., Renedo, A., McGowan, C.R. \& Portela, A., Effects of community participation on improving up take of skilled care for maternal and new born health: a systematic review. PLoS One. 8(2), 2008. doi: 10.1371/journal.pone.0055012 PMID: 23390509.

[7] Farnsworth, S.K., Bose, K., Fajobi, O., Souza, P.P., Peniston, A., Davidson, L.L. et al., Community engagement to enhance child survival and early development in low and middle-income countries: an evidence review. J Health Commun., 19, pp. 7-88, 2014. doi: 10.1080/10810730.2014.941519 PMID:25207448.

[8] Kenny, A., Hyett, N., Sawtell, J., Dickson-Swift, V., Farmer, J. \& O'Meara, P., Community participation in rural health: a scoping review. BMC Health Serv Res. 13:64, 2013. doi: 10.1186/1472-6963-13-64 PMID:23414561.

[9] Kenny, A., Farmer, J., Dickson-Swift, V. \& Hyett, N., Community participation for rural health: a review of challenges. Health Expect. 2014.

[10] Rifkin, S.B., Paradigms lost: toward a new understanding of community participation in health programmes. Acta Trop, 61(2), pp. 79-92, 1996. PMID: 8740887.

[11] Rifkin, S.B., A framework linking community empowerment and health equity: it is a matter of CHOICE.J Health Popul. Nutr., 21(3), pp. 168-80, 2003. PMID: 14717563.

[12] Atkinson, J., Vallely, A., Fitzgerald, L., Whittaker, M. \& Tanner, M., The architecture and effect of participation: a systematic review of community participation for communicable disease control and elimination. Implications for malaria elimination. Malaria Journal, 10(204), 2011.

[13] Campbell, C. \& Jovchelovitch, S., Health, Community and Development: Towards a Social Psychology of Participation. Journal of Community and Applied Social Psychology, 10, pp. 255-270, 2000.

[14] Navarro, V., A critique of the ideological and political positions of the Brandt Report and the Alma Ata Declaration. Int J Health Serv., 14(2), pp. 159-172, 1984. PMID: 6735536.

[15] Joffe, H., Risk: From perception to social representation. British Journal of Social Psychology, 42(1), pp. 55-73, 2003.

[16] Howarth, C., Towards a Social Psychology of Community: A Social Representations erspective. Journal for the Theory of Social Behaviour, 31(2), pp. 223-38, 2001.

[17] Howarth, C., Foster, J., Dorrer, N., Exploring the Potential of the Theory of Social Representations inCommunity-based Health Research-and Vice Versa? Journal of Health Psychology, 9(2) pp. 229-243, 2004.

[18] Joffe, H., Beyond the knowledge-attitude-behaviour paradigm of AIDS research. International Conferenceon AIDS, 9(955), 1993.

[19] Arnstein, S., A ladder of citizen participation. Journal of the American Institute of Planners, 35, pp. 216-224, 1969. 
[20] Rifkin, S.B., Community participation in maternal and child health/family planning programs. Geneva: World Health Organization, 1991.

[21] O'Rourke, K., Howard-Grabman, L. \& Seoane, G., Impact of community organization of women on perinatal outcomes in rural Bolivia. Rev PanamSaludPublica., 3(1), pp. 9-14, 1998. PMID: 9503957.

[22] Wallerstein, N., Powerlessness, empowerment, and health: implications for health promotion programs. Am J Health Promot, 6(3):197-205, 1992. PMID: 10146784.

[23] Rifkin, S.B., Lessons from community participation in health programmes: a review of the post Alma-Ataexperience. Int Health., 1(1), pp. 31-36, 2009. doi: 10.1016/j.inhe.2009.02.001 PMID: 24036293.

[24] Liberato, S.C., Brimblecombe, J., Ritchie, J., Ferguson, M. \& Coveney, J., Measuring capacity building in communities:a review of the literature. BMC Public Health.2011; 11:850. doi: 10.1186/1471-2458-11-850PMID: 22067213.

[25] Pathfinder International, Title: Home / our projects / NGO Health Services Delivery Project, website http://www.pathfinder.org/projects/ngo-health-service-deliveryproject/. 